\title{
Sinopse das espécies de Lamiales Bromhead ocorrentes nas restingas do Estado do Pará, Brasil ${ }^{1}$
}

\author{
Mônica Nazaré Rodrigues Furtado ${ }^{2}$, Ricardo de Souza $\mathrm{Secco}^{2}$ e Antônio Elielson Sousa Rocha ${ }^{2,3}$ \\ Recebido: 28.12.2011; aceito: 03.10.2012
}

\begin{abstract}
Synopsis of species of Lamiales Bromhead occurring in the coastal strand vegetation of Pará State, Brazil). This paper presents a taxonomic study on species of the Order Lamiales Bromhead in the coastal strand vegetation, know as restinga, in the State of Pará, Brazil. Restinga is a vegetation growing on sand coast of beaches and on dunes and represents a complex of different formations. Lamiales is represented in restingas by 24 species, included in seven families. Eleven species are new records to restingas of Pará State, and two are new to Amazonia. Key to species identification, as well as brief descriptions, illustrations and general comments are presented.
\end{abstract}

Key words: Amazônia, Eudicotyledonae, Lamiales, sandy coast of Pará

RESUMO - (Sinopse das espécies de Lamiales Bromhead ocorrentes nas restingas do Estado do Pará, Brasil). Este trabalho tem como objetivo o estudo taxonômico das espécies de Lamiales Bromhead nas restingas do Estado do Pará. A restinga é uma formação vegetacional, que cresce na areia branca das praias do mar e dunas, e apresenta um complexo de formações vegetais. Lamiales está representada por 24 espécies, incluídas em sete famílias. Onze espécies são novas ocorrências para as restingas do Pará e duas para a Amazônia. São apresentadas chaves para identificação das espécies, descrições resumidas, ilustrações e comentários gerais.

Palavras-chave: Amazônia, Eudicotyledonae, Lamiales, restingas do Pará

\section{Introdução}

As restingas amazônicas, até a década de 80, eram citadas apenas em estudos de classificação de vegetação (Pires 1973). A partir da publicação de Santos \& Rosário (1988), houve intensificação dos estudos nesta vegetação, especialmente nas restingas do Crispim (Marapanim) e Algodoal/Maiandeua (Maracanã), ambas no Estado do Pará. Nestes estudos foram abordados essencialmente aspectos floristicos e fitossociológicos (Bastos et al. 1995, Bastos 1996, Costa-Neto et al. 1996). Somente no final dos anos 90 foi publicado um estudo taxonômico sobre as Turneraceae (Vicente et al. 1999), o primeiro de uma série que vem sendo publicada como contribuição à Flórula Fanerogâmica das Restingas do Estado do Pará. Desde então, as seguintes famílias foram tratadas: Poaceae (Rocha 2000), Eriocaulaceae (Rocha \& Bastos 2004), Myrtaceae (Rosário et al. 2005), Arecaceae (Oliveira et al. 2009), Bignoniaceae
(Furtado et al. 2009, tratando apenas as espécies das ilhas de Algodoal e Maiandeua), Chrysobalanaceae (Martins et al. 2009), Ochnaceae (Lopes et al. 2009), Polygalaceae (Mesquita et al. 2009), Solanaceae (Andrade et al. 2009) e Rubiaceae (Margalho et al. 2009).

Aos poucos vem sendo desvendada e diagnosticada a flora das restingas da Amazônia, área não só de beleza turística, mas também de enorme diversidade florística. Dando continuidade a esses estudos, trataremos sucintamente a Ordem Lamiales das restingas do Estado do Pará, formada por sete famílias, abrangendo um total de 24 espécies, considerando que ainda não haviam recebido um estudo taxonômico atualizado nesse ecossistema.

\section{Material e métodos}

Área de estudo - O litoral paraense ocupa $500 \mathrm{~km}$ de extensão em relação à costa brasileira. Situa-se entre a

1. Parte da Dissertação de Mestrado do primeiro Autor

2. Museu Paraense Emilio Goeldi, Coordenação de Botânica, Avenida Perimetral 1901, 66077-830 Belém, PA, Brasil

3. Autor para correspondência: asrocha@museu-goeldi.br 
baia do Marajó e a foz do rio Gurupi, correspondendo a 8,6\% da área total do Estado do Pará (Furtado 1987). O litoral corresponde à Mesorregião Nordeste do Estado, formado pelos municípios paraenses limítrofes com o Oceano Atlântico, compondo a Zona Fisiográfica do Salgado e Bragantina, as quais apresentam diferentes tipos de vegetação, dentre elas as restingas, que se destacam como as mais restritas em relação aos outros ambientes (Bastos et al. 2001). Essas áreas estão distribuídas nos municípios de Marapanim, Maracanã, Curuçá, São João de Pirabas, Bragança, Salinópolis, Augusto Correa e Vizeu (Figura 1, baseada em Wessel \& Smith 1996).

O clima predominante no litoral paraense é do tipo "Awi", segundo a classificação de Köpen (Souza Filho et al. 2005). A precipitação pluviométrica anual é de 2500-3000 mm; a temperatura média anual é de $27^{\circ} \mathrm{C}$ e a umidade relativa do ar alcança valores médios anuais em torno de 80-85\% (Sudam 1984, Martorano et al. 1993).

A vegetação de restinga cobre grande parte da planície arenosa da costa amazônica e de acordo com Bastos et al. (2001) e Amaral et al. (2008) apresenta um complexo com seis formações vegetacionais: I. Halófila (sob a influência direta do mar, após a zona de estirâncio [praia], representada por poucas espécies); II. Psamófila reptante (sobre os primeiros cordões dunares, com as espécies estoloníferas, de rápido crescimento, fixadoras de dunas); III. Brejo herbáceo (com a maior diversidade de espécies, localizado no reverso do cordão dunar, em depressões alagadas); IV. Campo de dunas (formado por dunas altas intermediárias e interiores, sobre areia fina, com pequenos lagos na estação chuvosa); V. Formação aberta de moitas (fica nas áreas distantes da praia, com moitas de vários tamanhos, intercaladas por vegetação herbácea); VI. Floresta de restinga ou mata de Myrtaceae (sobre solos menos arenosos, fazendo limite com o mangue e a vegetação secundária (capoeira). Esse complexo inclui também o manguezal, seccionados por canais de marés e campus hipersalinos (apicuns).

Levantamento e tratamento do material - Foram levantadas todas as coleções de Lamiales coletadas nas restingas do litoral paraense, depositadas nos herbários: IAN, MG e HCDB.

Também foram realizadas coletas complementares durante os anos de 2008 e 2009, seguindo os métodos de Fidalgo \& Bononi (1984). As novas coletas foram incorporadas ao acervo do herbário MG.
As identificações foram baseadas nos trabalhos de Nowicke \& Epling (1969), Moldenke (1973), Taylor (1989), Wasshausen (1995), Gentry (1997), Hauk (1998), Harley (1999), Lohmann \& Hopkins (1999), Aymard (2005), Pool (2009) e Souza \& Giulietti (2009).

Os táxons são tratados por ordem alfabética de família, em descrições sucintas e com comentários adicionais, complementados pelas características morfológicas informadas na chave. Os dados de floração e frutificação foram obtidos com base nas informações das etiquetas de material de herbário e observações de campo.

\section{Resultados e Discussão}

\section{Lamiales Bromhead}

Ervas terrestres ou aquáticas, lianas, arbustos a árvores. Folhas simples ou compostas bi-trifolioladas, pubescentes ou glabras, tricomas simples ou ramificados; pecíolo canaliculado ou cilíndrico, às vezes curto ou ausente; estípulas presentes ou ausentes. Inflorescência em racemo, panícula, espiga, fascículo ou capítulo, terminal ou axilar; brácteas florais 1-12, pubescentes a glabras. Flores alvas, amarelas a avermelhas, bissexuadas, sésseis ou pediceladas; pedicelos canaliculados, cilíndricos, pubescentes, com tricomas simples, às vezes glabros; cálice concrescido ou livre, lobos/sépalas 2-5, pubescentes, tricomas simples, às vezes trífidos, podendo apresentar glândulas na face externa; corola concrescida, lobos 4-5, iguais ou irregulares, pubescentes, tricomas simples e ramificados, interna e externamente; estames 2-4, didínamos ou iguais, inclusos ou anteras exsertas, soldados na base da corola, anteras bitecas com conectivos, estaminódios 1-2; ovário súpero, estilete terminal, estigma bífido, capitado e indiviso. Fruto cápsula septicida ou drupa, com núculas.

A maioria das espécies estudadas ocorreu principalmente nas formações de brejo herbáceo, campo de dunas e floresta de restinga. Nenhuma espécie ocorreu na formação halófila, apenas Bignonia aequinoctialis L. (Bignoniaceae) foi encontrada próxima, na transição entre as psamófilas reptantes e o brejo herbáceo.

Nas restingas do Estado do Pará, a ordem está representada pelas seguintes famílias: Acanthaceae, Bignoniaceae, Lamiaceae, Lentibularaceae, Linderniaceae, Plantaginaceae e Verbenaceae. 


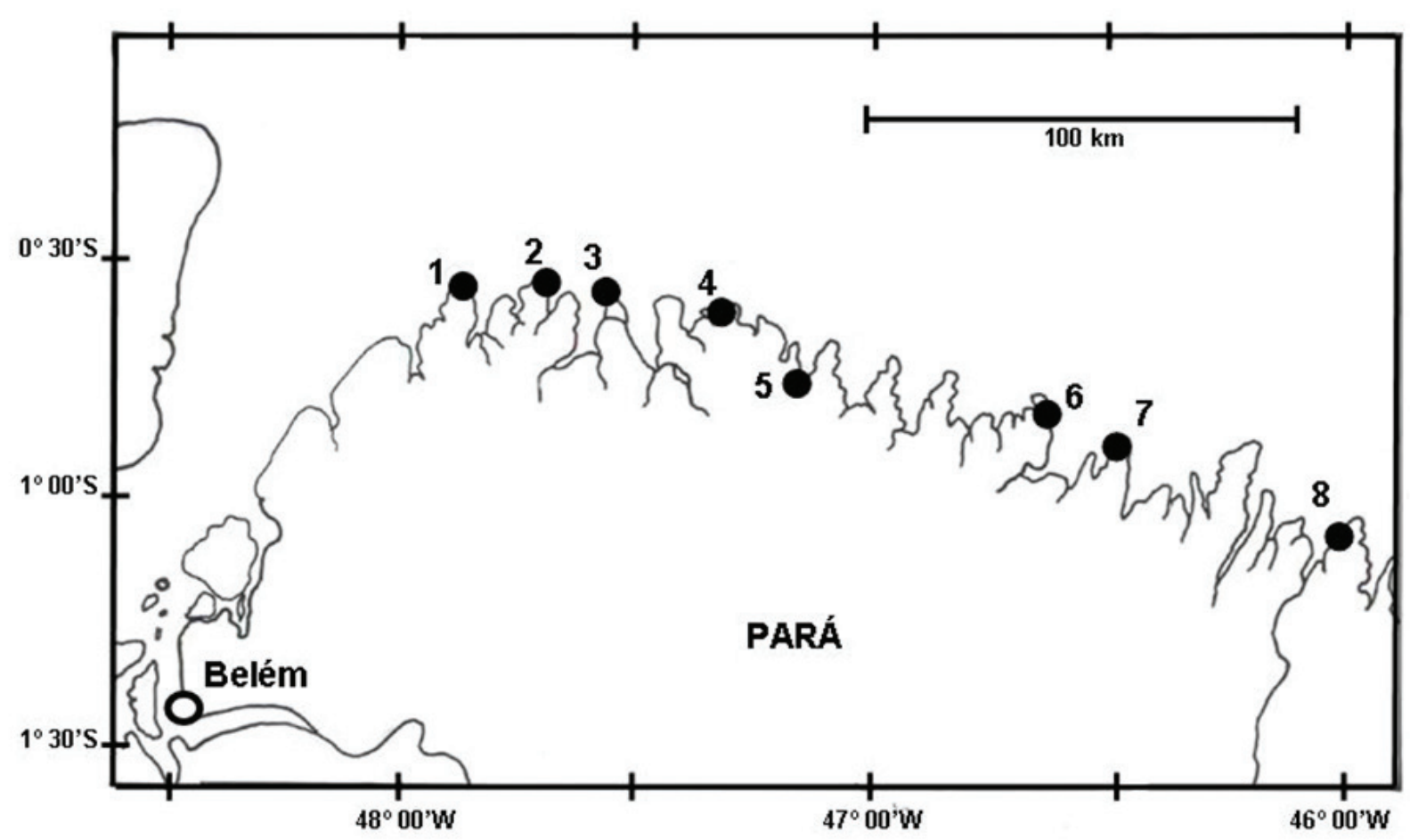

Figura 1. Localização da área estudada nas restingas do litoral do Estado do Pará, Brasil. 1. Curuçá, 2. Marapanim, 3. Maracanã, 4. Salinópolis, 5. São João de Pirabas, 6. Bragança, 7. Augusto Correia, 8. Vizeu (Wessel \& Smith 1996).

Figure 1. Location of restinga study areas of Pará State, Brazil. 1. Curuçá, 2. Marapanim, 3. Maracanã, 4. Salinópolis, 5. São João de Pirabas, 6. Bragança, 7. Augusto Correia, 8. Vizeu (Wessel \& Smith 1996).

Chave para identificação das espécies de Lamiales ocorrentes nas restingas do Estado do Pará

1. Plantas insetívoras, presença de estolões, rizóides e utrículos

2. Brácteas basifixas, não peltadas

3. Brácteas 3-partidas; lâmina foliar obovada a orbicular; corola roxa; escamas e brácteas foliáceas

4. Lábio inferior da corola inteiro

18. Utricularia tricolor

4. Lábio inferior da corola acentuadamente 3-lobado

13. Utricularia amethystina

3. Brácteas inteiras; lâmina foliar linear ou filiforme; corola amarela; escamas e brácteas fimbriadas ou denticuladas

5. Lábio superior da corola dividido, 2-lobado

14. Utricularia fimbriata

5. Lábio superior da corola inteiro, não lobado 16. Utricularia simulans

2. Brácteas livres, peltadas

6. Brácteas estéreis ausentes ao longo do pedicelo; palato quase igual ou um pouco maior que o lábio inferior 17. Utricularia subulata

6. Brácteas estéreis presentes, alternadas ao longo do pedicelo; palato muito maior que o lábio inferior 15. Utricularia pusilla

1. Plantas não insetívoras; ausência de estolões, rizóides e utrículos

7. Folhas compostas; presença de gavinha e campos interpeciolares

8. Folhas 3-folioladas; presença de tricomas ramificados nas faces da lâmina foliar; flores róseas

8. Folhas 2-folioladas; ausência de tricomas ramificados nas faces da lâmina foliar; flores alvas a lilases 
9. Campos interpeciolares presentes; estípula subconica 7. Tanaecium pyramidatum

9. Campos interpeciolares ausentes; estípula eliptico-oval a lanceolada

10. Estípula lanceolada eglandulosa; gavinha simples; disco na base do ovário ausente

4. Bignonia aequinoctialis

10. Estípula elíptico-oval glandulosa; gavinha trífida; disco na base do ovário presente 5.Distictella cuneifolia

7. Folhas simples; ausência de gavinha e campos interpeciolares

11. Cálice com sépalas soldadas

19. Lindernia crustacea

11. Cálice com sépalas livres

12. Limbo foliar com pontuações ou glândulas na superfície; inflorescência com até

10 brácteas

13. Ervas terrestres; inflorescência em espiga ou racemo

14. Inflorescência em espiga, sépalas desiguais, estigma bífido

22. Bacopa sessiliflora

14. Inflorescência em racemo, sépalas iguais, estigma indiviso

23. Scoparia dulcis

13. Ervas aquáticas; inflorescência com 2 flores

15. Lâmina foliar com ambas as faces glabras; brácteas filiformes

20. Bacopa bacopoides

15. Lâmina foliar pubescente somente na face abaxial; brácteas ausentes .... 21. Bacopa salzmannii

12. Limbo foliar sem pontuações ou glândulas na superfície; inflorescência com mais de

10 brácteas

16. Cálice 2-lobado; brácteas verdes cordadas; flores róseas; ausência de núculas ........ 24. Lippia alba

16. Cálice 5-lobado; brácteas vermelhas não cordadas; flores alvas, amarela-claras, violetas, roxas ou lilases; presença de núculas

17. Brácteas florais vistosas, vermelhas ou cor de vinho

18. Brácteas elíptico-lanceoladas; peciolo, nervuras e margem intensamente pubescentes com tricomas glandulares; superficie foliar pubescente

18. Brácteas obovadas; peciolo, nervuras e margem levemente pubescentes com tricomas simples; superfície foliar glabra 9. Amasonia obovata

17. Brácteas florais verdes ou ausentes

19. Cálice com sépalas livres, não denticulado; pedúnculo liso; venação do cálice presente nos lobos 12. Marsypianthes chamaedrys

19. Cálice com sépalas soldadas, denticulado; pedúnculo escamoso; venação do cálice ausente nos lobos

20. Erva ou arbusto

21. Flores vermelhas 1. Thyrsacanthus secundus

21. Flores alvas, violetas ou arroxeadas

22. Brácteas em periclinio presente; flores pediceladas; cálice com venação na horizontal e vertical 10. Hyptis atrorubens 22. Brácteas em periclinio ausente; flores sésseis; cálice com 20. Árvore venação somente na vertical 11. Hyptis suaveolens

23. Raque da inflorescência cilídrica, corola pilosa externa e internamente 2. Avicennia germinans

23. Raque da inflorescência tetragonal, corola pilosa apenas externamente 3. Avicennia schaueriana

\section{ACANTHACEAE}

1. Thyrsacanthus secundus (Leonard) A.L.A. Côrtes \& Rapini Taxon 59(3): 971. $2010 \equiv$ Anisacanthus secundus Leonard, Lloydia 2: 213. 1939.

Figura $3 \mathrm{e}, \mathrm{f}, \mathrm{g}$
Arbusto escandente, ca. 2,5 m alt., reconhecido pela inflorescência em racemo, terminais, flores com cálice campanulado, corola vermelha, brilhante, dois estames, com anteras alvas, exsertas.

Material examinado: BRASIL. PARÁ: Maracanã, Ilha de Algodoal/Maiandeua, campo de dunas, 23-V-2008, 
M.N.R. Furtado 30 (MG); Maracanã, 9-IV-1991, M.N. Bastos et al. 740 (MG); Maracanã, margem do lago temporariamente alagado, 14-VI-1994, M.N. Bastos et al. 1696 (MG); Maracanã, formação aberta de moitas, 25-IX-2003, M.N. Bastos et al. 1421 (MG); Maracanã, ilha do Marco, 13-I-1992, M.N. Bastos et al. 1177 (MG); Maracanã, praia da princesa, floresta de restinga, 23-VIII-1999, L. Carreira et al. 1406 (MG); Maracanã, campo de dunas, 5-X-2006, A.S. Mesquita 15 (MG); Maracanã, campo de dunas, 1-VII-1992, L.C. Lobato \& R. Nascimento 489 (MG); Marapanim, Crispim, floresta de restinga, 24-IV-2008, M.N.R. Furtado 19 (MG); Marapanim, campo de dunas, 8-V-1993, M.N. Bastos et al. 1361 (MG); Marapanim, 27-VIII-2003, A.C. Tavares et al. 306 (MG); Marapanim, 27-VIII-2003, S.W. Holanda et al. 17 (MG); Marapanim, 19-III-2004, A.M. Ferreira 25 (MG). Salinópolis, Praia de Marieta, campo de dunas, 25-V-2005, A.E.S. Rocha et al. 290 (MG); Salinópolis, praia da Atalaia, campo de dunas, 20-VIII-2007, A.E.S. Rocha et al. 672 (MG).

Distribuição: Guiana, Guiana Francesa, no Suriname e Brasil (Wasshausen 1995). Encontrada em campo de dunas, formação aberta de moitas, floresta de restinga e na margem dos lagos periodicamente alagados. Apesar de ser extremamente comum, essa espécie é uma nova ocorrência para as restingas do Estado do Pará. Floresce entre janeiro e outubro. As raízes são consideradas afrodisíacas pelos moradores locais.

2. Avicennia germinans (L.) L., Sp. Pl., ed. 3. 891. $1764 \equiv$ Bontia germinans L., Syst. Nat., ed. 10. 2: 1122. 1759.

Figura 3 h, i, j, 1

Árvore, 4-5 m alt., reconhecida pela raque da inflorescência cilíndrica, flores com a corola variando de coloração, inicialmente amarela, depois tornando-se alva, mas permanecendo amarela ou laranja na fauce, pilosa externa e internamente, e fruto pubescente.

Material examinado: BRASIL. PARÁ: Salinópolis, praia do Maçarico, 14-XI-1976, M.G. Silva 2841 (MG); Maracanã, Ilha de Algodoal/Maiandeua, praia da Princesa, 14-XI-1993, M.N. Bastos et al. 1453 (MG); Maracanã, Ilha de Algodoal/Maiandeua, praia da Princesa, 22-VIII-1999, L. Carreira et al. 1343 (MG); Maracanã, Ilha de Algodoal/Maiandeua, mangue, 1-III-1988, M.N. Bastos et al. 546 (MG); Maracanã, Ilha de Algodoal/Maiandeua, praia da Princesa, 25-IX-1993, M.N. Bastos et al. 1428 (MG); Maracanã, Ilha de Algodoal/Maiandeua, Ilha de Fortalezinha, vegetação de restinga, 5-20-XII-1999,
L.C.B. Lobato et al. 2486 (MG); Bragança, praia de Ajuruteua, vegetação campo de dunas próximas a margem do mangue, 8-XII-1993, J. Sales \& C. Rosário 1993 (MG); Bragança, praia de Ajuruteua, mangue próximo do brejo herbáceo, 14-XI-1993, M.N. Bastos et al. 1453 (MG); São Caetano de Odivelas, furo do São João, 15-16-IV-1999, A. Lins et al. 852 (MG).

Distribuição: Venezuela, Guiana Francesa, Suriname, Guiana, Colômbia, Equador, Peru e Brasil; Estados Unidos e México (Aymard 2005).

Essa espécie é característica de manguezais, sendo encontrada nas restingas em virtude das sementes serem transportadas por canais de marés, desenvolvendo-se em regiões mais baixas, onde o solo permanece úmido por muitos meses. Floresce e frutifica de setembro a abril.

Nome popular: mangue branco (Moldenke 1973).

Avicennia germinans separa-se imediatamente de A. schaueriana pela raque da inflorescência cilíndrica e corola pilosa externa e internamente (vs. raque da inflorescência tetragonal e corola pilosa apenas externamente em A. schaeuriana).

3. Avicennia schaueriana Stapf. \& Leechm. ex Moldenke, Lilloa 4: 336. 1939.

Figura $3 \mathrm{~m}, \mathrm{n}, \mathrm{o}, \mathrm{p}$

Árvore, $18 \mathrm{~m}$ alt., reconhecida pela raque da inflorescência tetragonal, glabra, flores com a corola alva, pilosa externamente, estames com anteras exsertas, sem tricomas e fruto pubescente, velutino

Material examinado: BRASIL. PARÁ: Salinópolis, Maçarico, 10-VII-1974, G.T. Prance 21149 (MG); Bragança, Ilha de Canela, restinga, 17-VI-1995, J.U.M dos Santos \& L.C.B. Lobato 158 (MG).

Distribuição: Trinidad, Guiana, Suriname, Guiana Francesa e Brasil (Aymard 2005). Ocorre em manguezal. Essa espécie é uma nova ocorrência para a área de estudo. Floresce e frutifica de junho a agosto. Avicennia germinans e $A$. schaueriana são as únicas espécies arbóreas típicas dos manguezais a ocuparem o ecossistema de restinga no Estado.

\section{BIGNONIACEAE}

4. Bignonia aequinoctialis L., Sp. P1. 2: 623. $1753 \equiv$ Cydista aequinoctialis (L.) Miers, Proc. Roy. Hort. Soc. London 3: 191. 1863.

Figura $5 \mathrm{a}, \mathrm{b}, \mathrm{c}$

Liana, com glândulas ou pontuações escuras na maioria das partes vegetativas (ramos, folhas e 
nervuras) e reprodutivas (cálice, corola, pedicelo e estigma) e gavinhas simples, reconhecida pelas estípulas lanceoladas, eglandulosas, flores com a corola alva, os lóbulos rosados e pubescentes.

Material examinado: BRASIL. PARÁ: APA Algodoal/ Maiandeua, campo de dunas, 4-IX-2009, M.N.R. Furtado et al. 40 (MG); APA Algodoal/Maiandeua, floresta de restinga, 5-IX-2009, M.N.R. Furtado et al. 46 (MG); APA Algodoal/Maiandeua, floresta de restinga, 4-X-2006, M.N.R. Furtado et al. 01 (MG); APAAlgodoal/Maiandeua, floresta de restinga, 4-X-2006, M.N.R. Furtado et al. 02 (MG); APA Algodoal/Maiandeua, praia da Princesa, campo de dunas, 23-VIII-1999, L. Carreira et al. 1376 (MG); Vizeu, ilha de Jatium-Jabutitiua, vegetação de restinga, transição entre psamófila reptante e brejo herbáceo, 6-XI-1999, L.C.B. Lobato et al. 2515 (MG).

Distribuição: México, Índias Ocidentais, Venezuela, Bolívia e Brasil (Gentry 1997). Nas restingas do Estado do Pará, ocorre em dunas. Trata-se de um novo registro para as restingas do Estado do Pará. Floresce e frutifica entre agosto e novembro.

A característica que a distingue das demais espécies de Bignoniaceae ocorrentes nas restingas do Estado Pará é a ausência de tricomas nas partes vegetativas.

5. Distictella cuneifolia (DC.) Sandwith, Kew Bulletin, 1953: 476. 1954 EPithecoctenium cuneifolium DC., Prodr. 9: 184. 1845.

Figura $5 \mathrm{~d}, \mathrm{e}, \mathrm{f}$

Liana, sustentando-se em arbustos, através de gavinhas trífidas, reconhecida pelas estípulas elíptico-ovais, glandulosas, flores vistosas, corola alva a creme, apresentando cor amarela no interior do tubo, com cada um dos cinco lobos ramificando-se em mais um (bilobados), aparentemente crenados.

Material examinado: BRASIL. PARÁ: Maracanã, APA de Algodoa1/Maiandeua, restinga da praia da Princesa, 5-X-2006, M.N.R. Furtado et al. 19 (MG); Maracanã, APA de Algodoal/Maiandeua, restinga da praia da Princesa, campo de dunas, 22-V-2008, M.N.R. Furtado et al. 24 (MG); Maracanã, APA de Algodoal/ Maiandeua, restinga da praia da Princesa, 5-IX-2009, M.N.R. Furtado et al. 44 (MG); Marapanim, Crispim, floresta de restinga, 24-IV-2008, M.N.R. Furtado et al. 32 (MG).

Distribuição: Desde a Costa Rica até o Brasil (PA, MT) (Gentry 1973). Ocorre em campo de dunas e floresta de restinga. Floresce e frutifica entre abril e outubro.
Lohmann (2012) citou Amphilophium cuneifolium (DC.) L.G.Lohmann na Lista de Espécies da Flora do Brasil, entretanto, esta não constitui uma nova combinação válida, uma vez que a autora não fez a citação da obra princeps do basiônimo e nem a indicação da obra na qual estaria publicada a referida combinação

6. Arrabidaea cinnamomea (A.DC.) Sandwith, Candollea 7: 248. 1936 三 Bignonia cinnamomea A.DC., Prodr. 9: 184. 1845.

Figura $6 \mathrm{~m}$

Liana sustentada por árvores altas, reconhecida pelos tricomas ramificados, de cor amarelo-ouro, distribuídos por toda a planta, que a distingue das demais Bignoniaceae da área, além de folhas 3-folioladas e flores com corola rósea.

Material examinado: BRASIL. PARÁ: Marapanim, restinga da praia do Crispim, 24-III-2009, fl., M.N.R. Furtado 38 (MG).

Distribuição: Desde o México até a Argentina e Brasil (AP, AM e PA) (Lohmann \& Hopkins 1999). Ocorre em campo de dunas. Floresce em março.

Arrabidaea cinnamomea pode ser confundida com Fridericia nigrescens (Sandwith) L.G. Lohmann, espécie ocorrente na Amazônia e Maranhão, já que ambas possuem folhas 3 -folioladas, corola rósea e tricomas ramificados, mas diferem pelo fato de $A$. cinnamomea, quando seca, ter as folhas castanho-claras, com uma tonalidade acinzentada em algumas partes da lâmina foliar, principalmente no ápice. Essa afinidade gerou grande quantidade de identificações erradas em amostras de $A$. cinnamomea.

Lohmann (2012) citou Fridericia cinnamomea (DC.) L.G. Lohmann na Lista de Espécies da Flora do Brasil, entretanto, esta não constitui uma nova combinação válida, uma vez que a autora não fez a citação da obra princeps do basiônimo e nem a indicação da obra na qual estaria publicada a referida combinação.

7. Tanaecium pyramidatum (Rich.) L.G. Lohmann in Hokche, Cat. Fl. Vasc. Venezuela: 274. $2008 \equiv$ Bignonia pyramidata Rich., Actes Soc. Hist. Nat. Paris 1: 110. 1792.

Figura $6 \mathrm{j}, 1$

Liana, reconhecida por apresentar campos interpeciolares, ramos glabros, folíolos acinzentados quando secos, com as cascas dos ramos dourados, 
desprendendo-se, estípulas subconicas, folhas ovado-elípticas, corola lilás, internamente branca, tricomas moniliformes (em forma de rosário) na corola, cálice verde, com glândulas externas vistosas.

Material examinado: BRASIL. PARÁ: Maracanã. APA de Algodoal/Maiandeua., Mata da Rocinha, 20-24-IX-1994, M.N. Bastos \& L.C. Lobato 1741 (MG); Maracanã. APA de Algodoal/Maiandeua, campo de dunas próximo a praia da Princesa, 4-IX-2009, M.N.R. Furtado et al. 39 (MG); Maracanã. APA de Algodoal/Maiandeua, restinga da praia da Princesa, 12-IV-1991, M.N. Bastos et al. 739 (MG).

Distribuição: Desde o sul do México até o Brasil (Sandwith \& Hunt 1974, Hauk 1998). Ocorre em campo de dunas, na transição com o mangue. Floresce entre abril e setembro.

\section{LAMIACEAE}

8. Amasonia campestris (Aubl.) Moldenke, Torreya 34: 8. 1934 三Taligalea campestris Aubl., Hist. P1. Guiane 2: 625, t.252. 1775.

Figura $2 \mathrm{a}, \mathrm{b}, \mathrm{c}$

Arbusto, ca. $50 \mathrm{~cm}$ alt., reconhecido pelas folhas pubescentes, inflorescência em racemo terminal, pluriflora, flores com a corola amarelo-clara, com brácteas elíptico-lanceoladas, vermelhas, vistosas.

Material examinado: BRASIL. PARÁ: Maracanã, Ilha de Algodoal, praia da Princesa, 9-IV-1991, M.N. Bastos et al. 824 (MG); Maracanã, Ilha de Algodoal, praia da Princesa, 22-25-V-1994, M.N. Bastos et al. 1665 (MG); Maracanã, Ilha de Algodoal, restinga da praia da Marieta, 7-IX-1994, M.N. Bastos et al. 1767 (MG); 23-VIII-2007, Maracanã, Ilha de Algodoal, campo de dunas da praia da Princesa, A.E.S. Rocha et al. 714 (MG); Marapanim, restinga do Crispim, 19-III-2004, A.M. Ferreira 26 (MG); Marapanim, restinga do Crispim, floresta de restinga, 24-IV-2008, M.N.R. Furtado 20 (MG); Marapanim, restinga do Crispim, campo de dunas, 24-III-2009, M.N.R. Furtado 36 (MG). Augusto Corrêa, APA de Urumajó, Ilha de Camarauaçu, restinga, 9-III-2001, F. Peçanha \& F. Batista 09 (MG).

Distribuição: Guiana, Suriname, Guiana Francesa, Colômbia e Brasil (Aymard 2005). Ocorre em formação aberta de moitas, brejo herbáceo e campo de dunas. Floresce e frutifica entre março e setembro.
9. Amasonia obovata Gleason, Bull. Torrey Bot. Club. 58: 463. 1931.

Figura $2 \mathrm{~d}, \mathrm{e}, \mathrm{f}$

Arbusto, ca. $60 \mathrm{~cm}$ alt., reconhecido pelos ramos avermelhados, folhas quase glabras, esverdeadas, com a superfície brilhosa, flores com brácteas obovadas, vermelho-escuras ou cor de vinho, com margem pubescente, muito vistosas.

Material examinado: BRASIL. PARÁ: Bragança, Península de Ajuruteua, formação aberta de moitas, 18-VI-2005, fl., M.S. Neves 16 (HCDB).

Distribuição: Venezuela (Aymard 2005, Jansen-Jacobs $\&$ Aymard 2007) e Brasil (PA, AM, TO, PI e MT). Ocorre em campo de dunas. Floresce em junho.

10. Hyptis atrorubens Poit., Ann. Mus. Hist. Nat. 7: 466, t. 27, f. 3. $1806 \equiv$ Mesosphaerum atrorubens (Poit.) Kuntze, Revis. Gen. P1. 2: 525. 1891.

Figura $2 \mathrm{~g}, \mathrm{~h}, \mathrm{i}, \mathrm{j}$

Erva semi-prostrada, ca. $25 \mathrm{~cm}$ alt., reconhecida pela inflorescência, muito característica, cujas flores concentram, ao redor, um grande número de brácteas verdes, flores diminutas, pediceladas, alvas, dispostas em capítulos e cálice com venação horizontal e vertical.

Material examinado: BRASIL. PARÁ: Maracanã, APA de Algodoal/Maiandeua, restinga da praia da Princesa, 9-IV-1991, M.N. Bastos et al. 808 (MG); Maracanã, APA de Algodoal/Maiandeua, brejo herbáceo, 20-XII-1993, M.N. Bastos et al. 1504 (MG); Maracanã, APA de Algodoal/Maiandeua, ilha do Marco, sobre dunas primárias, 12-I-1992, M.N. Bastos et al. 897 (MG); Maracanã, APA de Algodoal/Maiandeua, ilha do Marco, campo de dunas, 22-V-2008, M.N.R. Furtado 21 (MG); Maracanã, APA de Algodoal/Maiandeua, ilha do Marco, campo de dunas, 4-IX-2009, M.N.R. Furtado 43 (MG). Marapanim, vila de Marudá, Praia do Crispim, 14-VI-1991, M.N. Bastos et al. 917 (MG). Marapanim, vila de Marudá, Praia do Crispim, campo de dunas, 15-VI-1991, M.N. Bastos et al. 969 (MG). Augusto Corrêa, APA de Urumajó, Ilha de Camarauaçu, campo de dunas, 11-III-2001, F. Peçanha \& F. Batista (MG).

Distribuição: México, América Central, Oeste da Índia, Oeste da África, Guiana Francesa, Suriname, Guiana, Colômbia, Equador, Peru, Bolívia, Brasil, Paraguai (Harley 1999). Ocorre em brejo herbáceo, campo de dunas e formação aberta de moitas. Floresce entre março e setembro. 

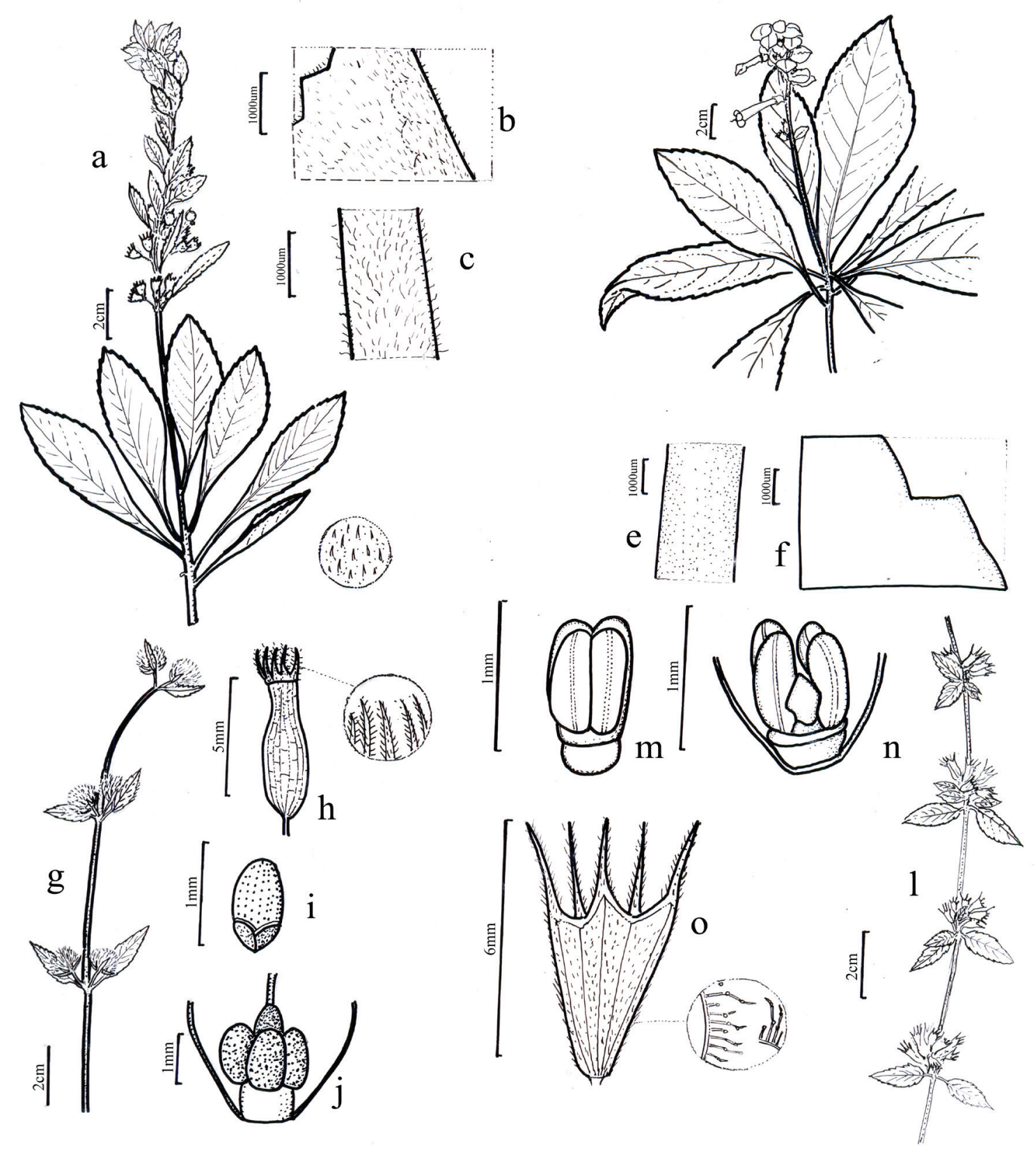

Figura 2. Espécies de Lamiales das restingas do Estado do Pará, Brasil. a-c. Amasonia campestris (Aubl.) Moldenke. a. Hábito com inflorescência. b. Detalhe da folha, com as nervuras secúndárias, terciárias e margem foliar com tricomas glandulares. c. Detalhe do pecíolo com tricomas glandulares. (a-c: M.N.R. Furtado 36). d-f. Amasonia obovata Gleason. d. Hábito com inflorescência. e. Detalhe do pecíolo levemente pubescente com tricomas simples. f. Corte da superfície foliar próximo da margem levemente pubescente com tricomas simples. (d-f: M.S. Neves 16). g-j. Hyptis atrorubens Poit. g. Hábito. h. Cálice denticulado pubescente, com tricomas setosos. i. Núcula. j. Ovário até a metade inserido entre as núculas (g: M.N.R. Furtado 21; h-j: M.N.R. Furtado 43). 1-o. Hyptis suaveolens (L.) Poit. 1. Hábito. m. Núculas. n. Ovário totalmente inserido nas núculas. o. Cálice denticulado com tricomas glandulares (1: A.E.S. Rocha et al. 750; n-o: M.N.R. Furtado 28).

Figure 2. Species of Lamiales from the restingas of Pará State, Brazil. a-c. Amasonia campestris (Aubl.) Moldenke. a. Habit with inflorescence. b. Detail of leaf with secondary and tertiary venation, and leaf margin with glandular trichomes. c. Detail of the petiole with glandular trichomes (a-c: M.N.R. Furtado 36). d-f. Amasonia obovata Gleason. d. Habit with inflorescence. e. Detail of slightly pubescent petiole with simple trichomes. f. Section of slightly pubescent foliar surface with simple trichomes close to the margin (d-f: M.S. Neves 16). g-j. Hyptis atrorubens Poit. g. Habit. h. Pubescent toothed calyx, with setose trichomes. i. Nutlets. j. Ovary with its lower-half part surrounded by nutlets (g: M.N.R. Furtado 21; h-j: M.N.R. Furtado 43). 1-o. Hyptis suaveolens (L.) Poit. 1. Habit. m. Nutlets. n. Ovary totally surrounded by nutlets. o. Toothed calyx with glandular trichomes (1: A.E.S. Rocha et al. 750; n-o. M.N.R. Furtado 28). 


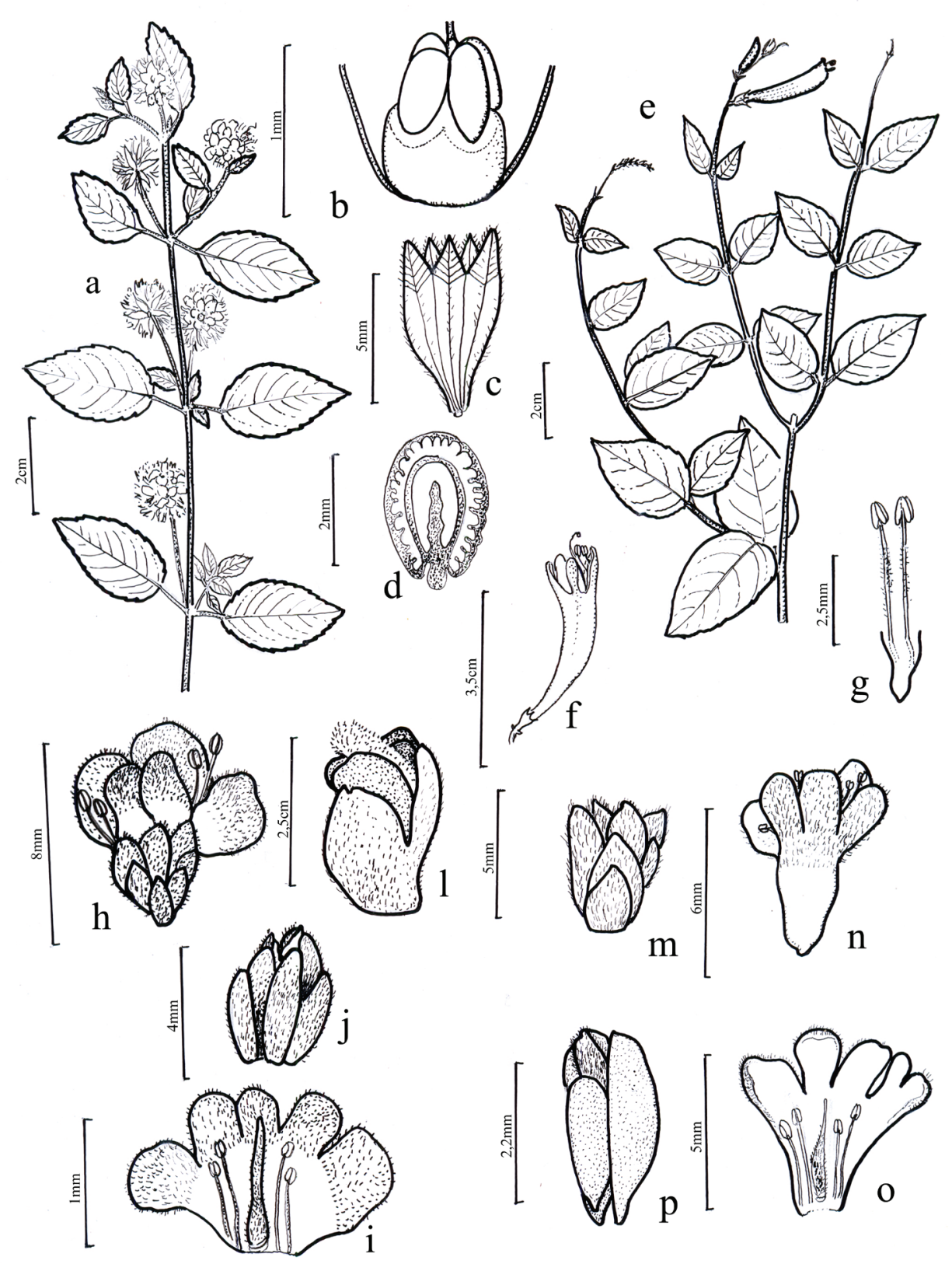

Figura 3. Espécies de Lamiales das restingas do Estado do Pará, Brasil. a-d. Marsypianthes chamaedrys (Vahl) Kuntze. a. Hábito com inflorescência. b. Ovário quase totalmente inserido nas núculas. c. Cálice. d. Núculas com face ventral fimbriada (a: A.E.S. Rocha \& L.C.B. Lobato 844; b-d: M.N.R. Furtado 47). e-g. Thyrsacanthus secundus Leonard. e. Hábito. f. Flor com anteras exsertas com tricomas simples e glandulares externamente. g. Androceu (e: M.N.R. Furtado 19; f-g: M.N.R. Furtado 30). h-1. Avicennia germinans (L.) L. h. Flor com anteras estames exsertas e tricomas simples cobrindo externamente o cálice e lobos da corola. i. Corola aberta com gineceu e androceu. j. Cálice com sépalas livres. 1. Cápsula aberta (h-1: M.N.C. Bastos et al. 546). m-p. Avicennia schaueriana Stapf. \& Leechm. ex Moldenke. $\mathrm{m}$. Cálice com sépalas livres e com tricomas simples externamente. n. Corola pubescente somente externamente. o. Corola aberta com gineceu e androceu. p. Fruto vertical aberto (m-p: J.U.M. Santos \& L.C.B. Lobato 15).

Figure 3. Species of Lamiales from restingas of Pará State, Brazil. a-d. Marsypianthes chamaedrys (Vahl) Kuntze. a. Habit with inflorescence. b. Ovary almost totally surrounded by nutlets. c. Calyx. d. Nutlets with fimbriate ventral facet (a: A.E.S. Rocha \& L.C.B.Lobato 844; b-d: M.N.R. Furtado 47). e-g. Thyrsacanthus secundus Leonard. e. Habit. f. Flower with exserted anthers with simple and glandular trichomes on the outside of its corolla. g. Androecium (e: M.N.R. Furtado 19; f-g: M.N.R. Furtado 30). h-1. Avicennia germinans (L.) L. h. Flower with exserted anthers, and simple trichomes externally covering the calyx and lobes of the corolla. i. Opened corolla with gynoecium and androecium. j. Calyx with free sepals. 1. Opened capsule (h-1: M.N.C. Bastos et al 546). m-p. Avicennia schaueriana Stapf. \& Leechm. ex Moldenke. m. Calyx with free sepals and simple trichomes on its outside surface. n. Corolla only externally pubescent. o. Opened corolla with gynoecium and androecium. p. Fruit vertically opened (m-p: J.U.M. Santos \& L.C.B. Lobato 15). 
11. Hyptis suaveolens (L.) Poit., Ann. Mus. Hist. Nat.7: 472, pl.29, f. 2. 1806 $\equiv$ Ballota suaveolens L., Syst. Nat. 2: 1100. 1759.

Figura $21, \mathrm{~m}, \mathrm{n}, \mathrm{o}$

Arbusto reptante, 1,8-2,0 m alt., reconhecido pelo caule com tricomas esbranquiçados, inflorescência axilar, folhas intensamente verdes, com certas partes do ápice e margem roxas ou violetas, flores sésseis, com corola violeta ou arroxeada, cálice com venação apenas na vertical.

Material examinado: BRASIL. PARÁ: Maracanã, Praia da Marieta, 23-VIII-2007, A.E.S. Rocha et al. 750 (MG); Maracanã, Ilha de Algodoal/Maiandeua, campo de dunas, 23-V-2008, M.N.R. Furtado 28 (MG).

Distribuição: Trópicos da Américas do Norte e Sul, também encontrada ao leste de Hong Kong, Austrália e África (Nowicke \& Epling 1969). Ocorre em campo de dunas. Essa espécie é uma nova ocorrência para a área de restinga da Amazônia. Floresce entre maio e agosto.

12. Marsypianthes chamaedrys (Vahl) Kuntze, Revis. Gen. P1. 2: 524. 1891 E Clinopodium chamaedrys Vahl, Symb. Bot. Upsal. 3: 77. 1794.

Figura $3 \mathrm{a}, \mathrm{b}, \mathrm{c}, \mathrm{d}$

Arbusto, ca. 1,5 m alt., com tricomas frequentes em toda a planta, reconhecido pelas folhas pegajosas, corola azul-violeta, cálice com sépalas livres, tendo a venação unida tanto na horizontal quanto na vertical, assemelhando-se a uma rede, e as núculas côncavas, com a parte interior fimbriada ou laciniada.

Material examinado: BRASIL. PARÁ: APA Algodoal/ Maiandeua, próximo a praia da Princesa, 7-IX-2009, M.N.R. Furtado et al. 47 (MG); Maracanã, praia da Marieta, campo de dunas, 24-28-XI-2007, A.E.S. Rocha \& L.C. Lobato 844 (MG).

Distribuição: México, América Central, oeste das Índias, sul do Brasil e Peru (Nowicke \& Epling 1969). Ocorre em campo de dunas. Essa espécie é uma nova ocorrência para o Pará. Floresce entre setembro e novembro

\section{LENTIBULARIACEAE}

13. Utricularia amethystina Salzm. ex A.St.-Hil. \& Girard, Compte Rend. Hebd. Séances Acad. Sci. 7: 870. 1838 E Calpidisca amethystina (Salzm. ex A. St.- Hil. \& Girard) Barnhart, Bull. Torrey Bot. Club 58: 468. 1931.

Figura $7 \mathrm{a}, \mathrm{b}, \mathrm{c}$
Erva terrestre, $8-12 \mathrm{~cm}$ alt., reconhecida pela corola roxa, com o lábio inferior acentuadamente 3-lobado, e brácteas 3-partidas, conadas na base.

Material examinado: BRASIL. PARÁ: Maracanã, Ilha de Algodoal/Maiandeua, restinga da praia da Princesa, 22-25-V-1994, M.N. Bastos et al. 1651 (MG); Maracanã, Ilha de Algodoal/Maiandeua, restinga da praia da Princesa, 13-VI-1994, M.N. Bastos et al. 1688 (MG).

Distribuição: Da Flórida ao Brasil (Taylor 1976). Ocorre em formação arbustiva aberta. Floresce entre maio e junho.

14. Utricularia fimbriata Kunth, Nov. Gen. Sp. 2: 225.1817 三 Aranella fimbriata (Kunth) Barnhart, Fl. Miami 171. 1913.

Figura $7 \mathrm{~g}, \mathrm{~h}, \mathrm{i}, \mathrm{j}$

Erva terrestre, $11-15 \mathrm{~cm}$ alt., reconhecida pelas flores com lábio superior da corola 2-lobado, o inferior trilobado.

Gibson (1974) observou variação no tamanho do pedicelo de $U$. fimbriata de $1 \mathrm{a} 10 \mathrm{~mm}$ comp. Nas amostras de $U$. fimbriata coletadas nas restingas do Estado do Pará, o pedicelo apresentou-se com variação de 0,5 a $1,5 \mathrm{~mm}$ de comp.

Material examinado: BRASIL. PARÁ: Maracanã, Ilha de Algodoal/Maiandeua, campo de restinga, 12-VI-1994, M.N. Bastos et al. 1674 (MG); Maracanã, Ilha de Algodoal/Maiandeua, campo de restinga, 22-25-V-1994, M.N. Bastos et al. 1653 (MG); Maracanã, Ilha de Algodoal/Maiandeua, entre dunas, 19-26-VI-1991, M.N. Bastos et al. 866 (MG).

Distribuição: África Tropical, oeste da Índia, América Central e Sul (Taylor 1964). Ocorre em mata da restinga, próximo ao mangue e às dunas. Floresce entre maio e junho.

15. Utricularia pusilla Vahl, Enum. Pl. 1: 202. $1804 \equiv$ Setiscapella pusilla (Vahl) Barnhart ex Britton \& Wilson, Sci. Surv. Porto Rico \& Virgin Islands 6: 191. 1925.

Figura $6 \mathrm{e}, \mathrm{f}, \mathrm{g}, \mathrm{h}, \mathrm{i}$

Erva terrestre, ca. $12 \mathrm{~cm}$ alt., reconhecida pela corola amarela, com lábio inferior trilobado, e brácteas estéreis alternadas ao longo do pedicelo.

Material examinado: BRASIL. PARÁ: Bragança, Península de Ajuruteua, Vila Bonifácio, restinga, 17-VII-2006, R.M. Silva 175 (HCDB). 
Distribuição: Do México a Argentina (Taylor 1999). Ocorre em brejo herbáceo e campo de dunas. Essa espécie é um novo registro para a restinga da Amazônia. Floresce em julho.

Olvera (1996) comentou que frequentemente Utricularia pusilla Vahl é confundida com U. subulata L., pois ambas têm flores com corola amarela, lábio inferior trilobado e o racemo helicoidal. Porém, $U$. pusilla é diagnosticada pelas brácteas alternadas e estéreis ao longo do pedicelo e por apresentar o palato muito maior que o lábio inferior.

16. Utricularia simulans Pilg., Notizbl. Königl. Bot. Gart. Berlin. 6(56): 189. 1914 三 Polypompholyx bicolor Klotzsch, Reis. Br. Guiana: 1160. 1848.

Figura 7 1, m, n, o

Erva terrestre, 6,5-10 $\mathrm{cm}$ compr., reconhecida pelo escapo parcialmente achatado ou retorcido, corola amarela, com lábios superior e inferior inteiros, e brácteas auriculadas.

Material examinado: BRASIL. PARÁ: Maracanã, Ilha de Maiandeua, restinga, 26-X-2000, D.T. Costa et al. 99 (MG).

Distribuição: África, América tropical e subtropical, da Flórida ao Paraguai e Brasil (Pott \& Pott 2000). Ocorre em brejo herbáceo e campo de dunas. Essa espécie é uma nova ocorrência para as restingas do Estado do Pará. Floresce em outubro.

Segundo Olvera (1996), Utricularia simulans Pilg. pode ser confundida com U. fimbriata por apresentarem brácteas, brácteolas e escamas fimbriadas, porém $U$. fimbriata apresenta racemo alargado, muitas flores e brácteas não auriculadas. Nas amostras das restingas do Estado do Pará, onde as duas espécies ocorrem, ambas apresentam brácteas auriculadas; a diferença está nas bractéolas, com aurícula presente em U. fimbriata e ausente em U. simulans. Além disso, em $U$. simulans o lábio superior da corola é inteiro, sendo 2-lobado em U. fimbriata.

17. Utricularia subulata L., Sp. Pl. 1: 18. $1753 \equiv$ Setiscapella subulata (L.) Barnhart, Fl. Miami 170: 1913.

Figura $6 \mathrm{a}, \mathrm{b}, \mathrm{c}, \mathrm{d}$

Erva terrestre, 8-16 cm alt., reconhecida pelas flores distribuídas de forma helicoidal no racemo, com escamas e brácteas peltadas, livres, basisolutas (Mittelstaedt 2008), cálice rosado ou avermelhado, com nervuras proeminentes, não atingindo a margem, palato pubescente, principalmente na porção mediana, lábio inferior da corola acentuadamente 3-lobado, palato quase igual ou um pouco maior que o lábio inferior.

Material examinado: BRASIL. PARÁ: Maracanã, Ilha de Algodoal/Maiandeua, restinga da praia da Princesa, 22-25-V-1994, M.N. Bastos et al. 1635 (MG); idem, M.N. Bastos et al. 1652 (MG); Maracanã, Ilha de Algodoal/Maiandeua, brejo herbáceo e campo entre dunas, 22-V-2008, A.E.S. Rocha 1035 (MG); Maracanã, Ilha de Algodoal/Maiandeua, brejo, 5-IX-2009, M.N.R. Furtado et al. 45 (MG).

Distribuição: Pantropical (Corrêa \& Mamede 2002). Ocorre em brejo herbáceo e campo de dunas. Nas restingas do Estado do Pará, U. subulata é encontrada frequentemente em depressão úmida ou nas margens de lago temporário, nas formações vegetais de brejo e campo entre dunas. Apresenta dispersão bastante expressiva nas restingas do litoral paraense. Floresce entre maio e setembro.

18. Utricularia tricolor A.St.-Hil., Voy. Distr. Diam. 2: 418: 1833 EUtricularia chamissonis Weber ex Benj., Fl. Bras. 10: 241.1847.

Figura $7 \mathrm{~d}, \mathrm{e}, \mathrm{f}$

Erva terrestre, $12-26 \mathrm{~cm}$ alt., reconhecida pelas folhas obovadas, flores pediceladas, corola roxa, com lábio inferior inteiro e brácteas 3-partidas, com a porção mediana proeminente ou maior que as demais, o lobo superior sendo quase o dobro do lobo inferior do cálice.

Material examinado: BRASIL. PARÁ: Maracanã, Ilha de Maiandeua, restinga. 26-X-2000, D.T. Costa et al. 97 (MG).

Distribuição: América do Sul (Taylor 1999). Ocorre em brejo herbáceo e campo de dunas. Essa espécie é uma nova ocorrência para as restingas do Estado do Pará. Floresce e frutifica em outubro.

Essa espécie pode ser confundida com $U$. amethystina, pelo fato de ambas possuírem folhas obovadas, flores pediceladas, roxas, brácteas 3-partidas e bractéolas ausentes, mas se diferenciam pelo lábio inferior da corola 3-lobado apenas em U. amethystina.

\section{LINDERNIACEAE}

19. Lindernia crustacea (L.) F.Muell., Syst. Census Austral. Pl. 1: 97.1882 三 Capraria crustacea L., Syst. Nat. 12(2): 419. 1767.

Figura 4 1, m, n 
Erva rastejante, $8 \mathrm{~cm}$ alt., reconhecida pelas folhas deltóides, flores com corola violeta-azulada, dois estaminódios claviformes e cálice pubescente, com tricomas simples.

Material examinado: BRASIL. PARÁ: Bragança, Península de Ajuruteua, 20-VI-2003, C.C.L. Santos 39 (HCDB).

Distribuição: Pantropical. Áreas abertas e úmidas (Souza \& Giulietii 2009). Ocorre em dunas e mata de restinga. Essa espécie é uma nova ocorrência na área de estudo. Floresce e frutifica em junho.

\section{PLANTAGINACEAE}

20. Bacopa bacopoides (Benth.) Pulle, Enum. Vasc. Pl. Surinam: 415. $1906 \equiv$ Herpestis bacopoides Benth., Prodr. 10: 399. 1846.

Figura $4 \mathrm{a}, \mathrm{b}, \mathrm{c}$

Erva, $20 \mathrm{~cm}$ alt., reconhecida pelas flores com corola alva, brácteas filiformes, bastante perceptíveis no pedicelo (figura 4c) e se diferencia das demais espécies de Bacopa da área de estudo pela ausência de pubescência nas estruturas morfológicas.

Material examinado: BRASIL. PARÁ: Bragança, Península de Ajuruteua, Salinas dos Rosques, 20-V-2007, L.O. Santos 321 (HCDB).

Distribuição: Guatemala ao Brasil (Barringer \& Burger 2000). Ocorre em campo de dunas. Essa espécie é uma nova ocorrência para as restingas do Estado do Pará e para o Brasil. A espécie não está citada na Lista do Brasil (Souza 2012). Floresce e frutifica em maio.

21. Bacopa salzmannii (Benth.) Wettst. ex Edwall, Bol. Commiss. Geogr. Estado São Paulo 13: 175. $1897 \equiv$ Hespestis salzmannii Benth., Companion Bot. Mag. 2: 58. 1836.

Figura $4 \mathrm{~d}, \mathrm{e}, \mathrm{f}$

Erva aquática, $20 \mathrm{~cm}$ alt., reconhecida pelos tricomas esbranquiçados espalhados na planta, folhas sésseis, levemente amplexicaules, orbiculares a ovais, pubescentes na face abaxial, flores com corola alva a azulada, sépalas ovadas a elíptico-lanceoladas e lineares a filiformes, que permanecem nos frutos.

Material examinado: BRASIL. PARÁ: Bragança, Península de Ajuruteua, 19-VI-2004, M.M.O. Abreu 143 (HCDB).
Distribuição: Sul do México, América Central, Colômbia, Guiana, Peru, Brasil (ocorre em todo território brasileiro), Bolívia e Paraguai (Holmgren \& Vincent 2005). Primeiro registro para área de restinga (Souza 2012). Essa espécie é uma nova ocorrência para as restingas do Estado do Pará, sendo encontrada em brejo herbáceo e campo de dunas. Floresce e frutifica em junho.

22. Bacopa sessiliflora (Benth.) Wettst. ex Edwall, Bol. Commiss. Geogr. Estado São Paulo 13: 175. $1897 \equiv$ Herpestis sessiliflora Benth., Companion Bot. Mag. 2: 58. 1836.

Figura $5 \mathrm{~g}, \mathrm{~h}, \mathrm{i}, \mathrm{j}$

Subarbusto, 40-60 cm alt., reconhecido pelas folhas com ambas as faces levemente pubescentes, inflorescências em espiga terminal ou fascículo axilar, flores com a corola alva, sépalas desiguais e estigma bífido.

Material examinado: BRASIL. PARÁ: Maracanã, Ilha de Algodoal/Maiandeua, Rocinha, 8-V-1993, M.N. Bastos et al. 1390 (MG); Maracanã, Ilha de Algodoal/Maiandeua, Rocinha, 22-25-V-1994, M.N. Bastos et al. 1648 (MG); Maracanã, Ilha de Algodoal/ Maiandeua, campo de dunas, 4-IX-2009, M.N.R. Furtado et al. 42 (MG); Marapanim, praia do Crispim, 15-VI-1991, M.N. Bastos et al. 982 (MG); Augusto Corrêa, vila Perimerim, Urumajó, 16-IX-1999, L. Carreira \& F. Cardoso 1555 (MG).

Distribuição: México, América Central, Cuba, Colômbia, Guyana, Suriname, Guiana Francesa, Equador e Brasil (Holmgren \& Vincent 2005). Ocorre no Amapá, Pará, Amazonas, Acre, Maranhão, Ceará e Pernambuco). Primeiro registro para área de restinga (Souza 2012). Essa espécie é uma nova ocorrência para o Estado do Pará, sendo encontrada em formação aberta de moitas e campo de dunas. Floresce e frutifica entre maio e setembro.

23. Scoparia dulcis L., Sp. Pl. 1: 116. 1753.

Figura $51, \mathrm{~m}, \mathrm{n}$

Arbusto, $25-50 \mathrm{~cm}$ alt., reconhecido pela presença de lenticelas ou glândulas escuras nos ramos, folhas, cálice e pedicelos, tricomas apenas na base dos nós, entrenós e da corola, e glanduloso-pontuada em todas nas demais partes (Souza \& Giulietti 2003); folhas com margem serreada, principalmente na porção mediana e superior, inflorescência em racemo, flores com a corola rotácea, alva, sépalas desiguais, estigma indiviso. 

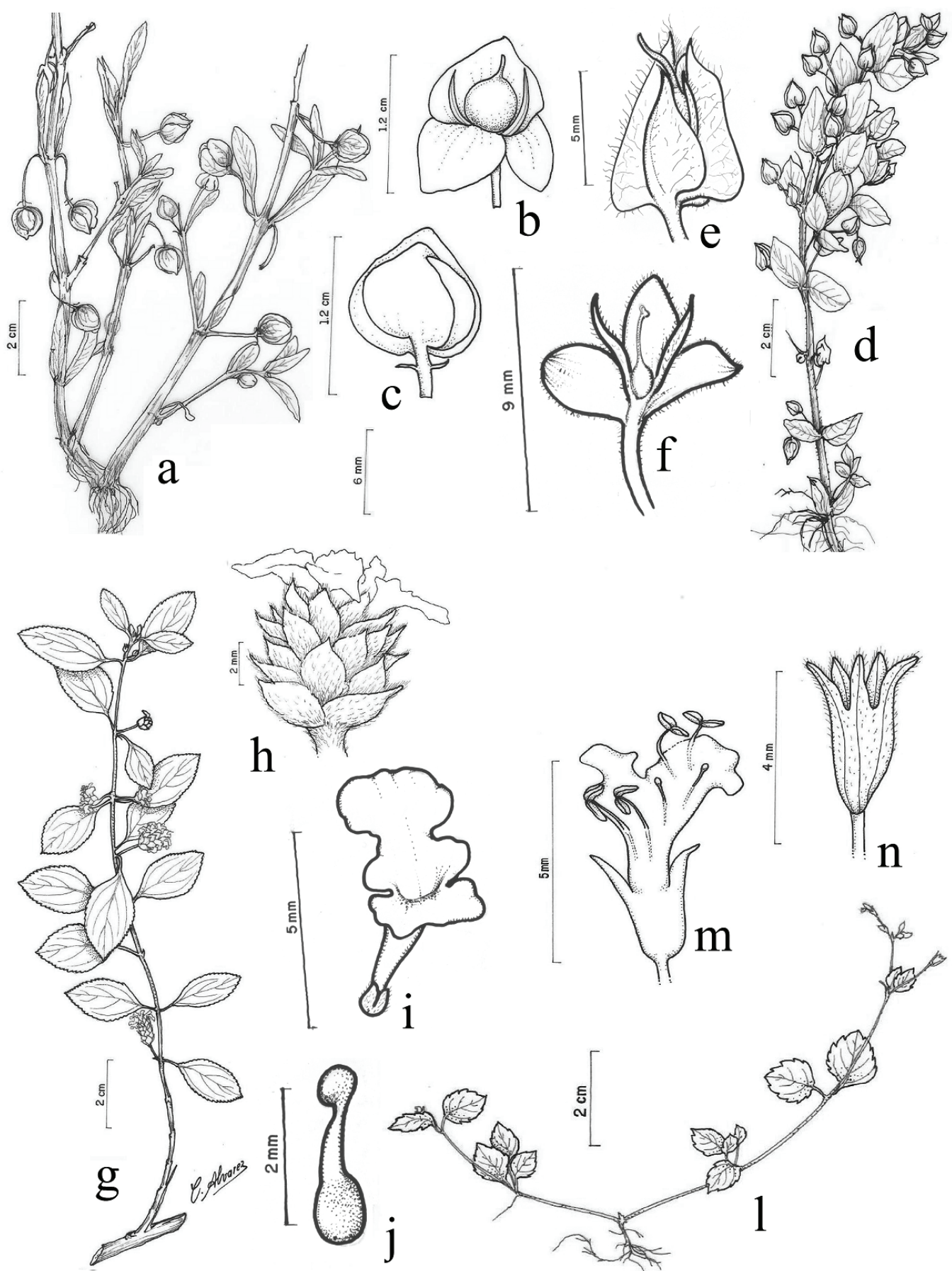

Figura 4. Espécies de Lamiales das restingas do Estado do Pará, Brasil. a-c. Bacopa bacopoides (Benth.) Pulle. a. Hábito; b. Fruto com cálice persistente. c. Cálice e brácteas inseridas na base do pedicelo (a-c: J.U.M. Santos 321). d-f. B. salzmannii (Benth.) Wettst. ex Edwall. d. Hábito. e. Fruto com cálice persistente. f. Gineceu inserido no cálice. (d-f: M.O. Abreu 143). g-j. Lippia alba (Mill.) N.E.Br. g. Hábito. h. Inflorescência com brácteas. i. Corola e cálice (sépalas 2). j. gineceu. (g-j: R.M. Silva 81). 1-n. Lindernia crustacea (L.) F.Muell. 1. Hábito. m. Flor com estames e estaminódios. n. cálice. (1-n: J.U.M. Santos 39).

Figure 4. Species of Lamiales from restingas of Pará State, Brazil. a-c. Bacopa bacopoides (Benth.) Pulle. a. Habit. b. Fruit with persistent calyx. c. Calyx and bracts inserted on the base of the pedicel. (a-c: J.U.M. Santos 321). d-f. B. salzmannii (Benth.) Wettst. ex Edwall. d. Habit. e. Fruit with persistent calyx. f. Gynoecium inserted on the calyx. (d-f: M.O. Abreu 143). g-j. Lippia alba (Mill.) N.E.Br. g. Habit. h. Inflorescence with bracts. i. Corolla and calyx (sepals 2). j. Gynoecium. (g-j: R.M. Silva 81). 1-n. Lindernia crustacea (L.) F.Muell. 1. Habit. m. Flower with stamens and staminodes. n. Calyx. (1-n: J.U.M. Santos 39). 


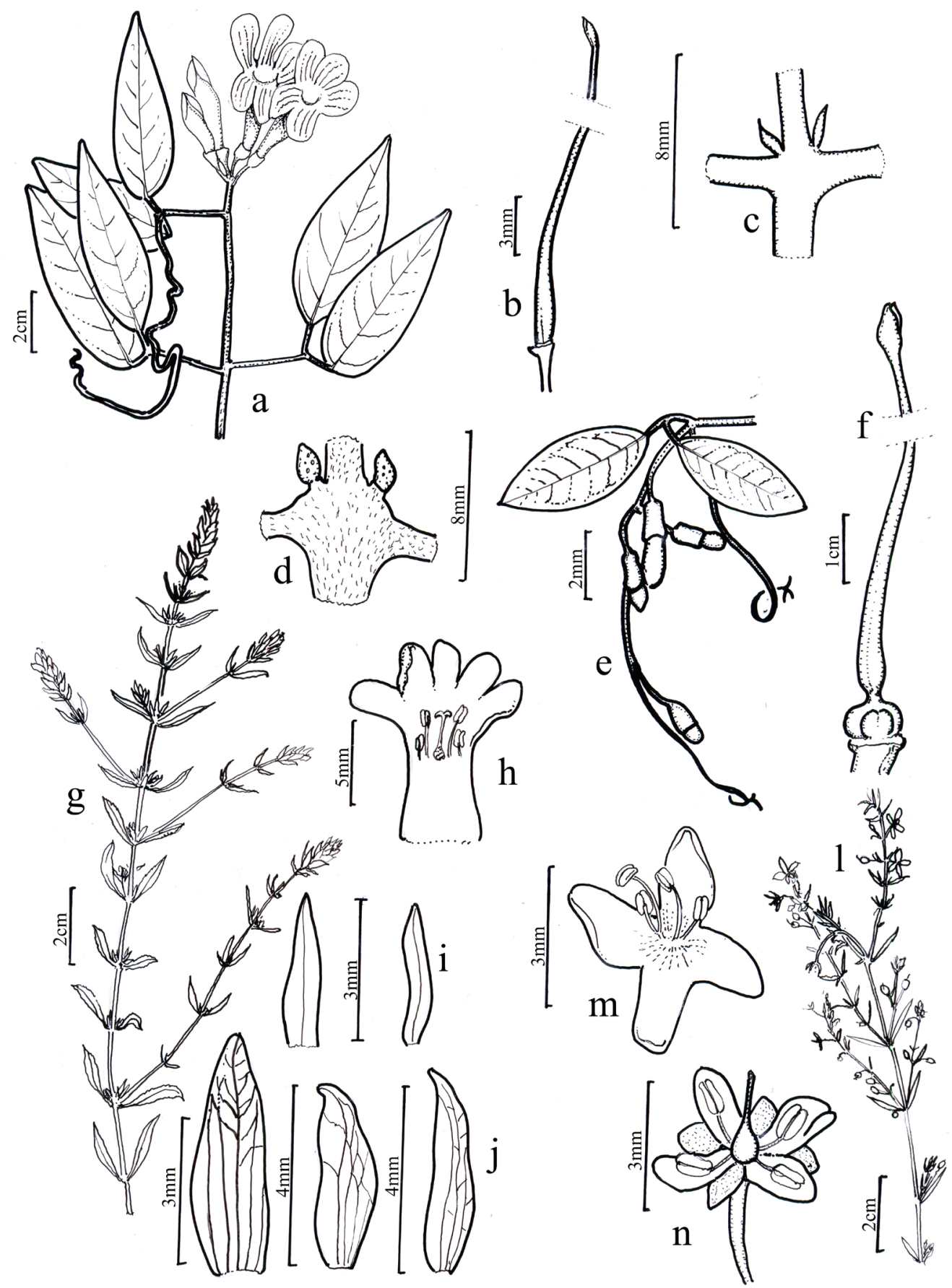

Figura 5. Espécies de Lamiales das restingas do Estado do Pará, Brasil. a-c. Cydista aequinoctialis (L.) Miers. a. Hábito com gavinha simples. b. Ovário. c. Detalhe do ramo com estipulas. (a-c: M.N.R. Furtado et al. 40). d-f. Distictella cuneifolia (DC.) Sandwith. d. Detalhe do ramo com estipulas. e. Hábito e ramo com gavinha trifida. f. Ovário com disco presente. (d: M.N.R. Furtado et al. 19; e-f: M.N.R. Furtado et al. 32). g-n. Bacopa sessiliflora (Benth.) Wettst. ex Edwall. g. Hábito. h. Corola aberta com androceu e gineceu. i. 2 Lobos internos do cálice. j. 3 Lobos externos do cálice. Scoparia dulcis L. 1. Hábito. m. Corola aberta com os estames. n. Flor aberta com androceu e gineceu.(1-n: M.N.R. Furtado \& A.E.S. Rocha 26).

Figure 5. Species of Lamiales from restingas of Pará State, Brazil. a-c. Cydista aequinoctialis (L.) Miers. a. Habit with simple tendril. b. Ovary. c. Detail of the stem with stipules (a-c: M.N.R. Furtado et al. 40). d-f. Distictella cuneifolia (DC.) Sandwith. d. Detail of the stem with stipules. e. Habit with trifid tendril. f. Ovário with disc. (d: M.N.R. Furtado et al. 19; e-f: M.N.R. Furtado et al. 32). g-n. Bacopa sessiliflora (Benth.) Wettst. ex Edwall. g. Habit. h. Opened corolla with androecium and gynoecium. i. 2 Internal lobes of the calyx. j. 3 External lobes of calyx. Scoparia dulcis L. 1. Habit. m. Opened corolla with stamens. n. Opened flower with androecium and gynoecium. (1-n: M.N.R. Furtado \& A.E.S. Rocha 26). 

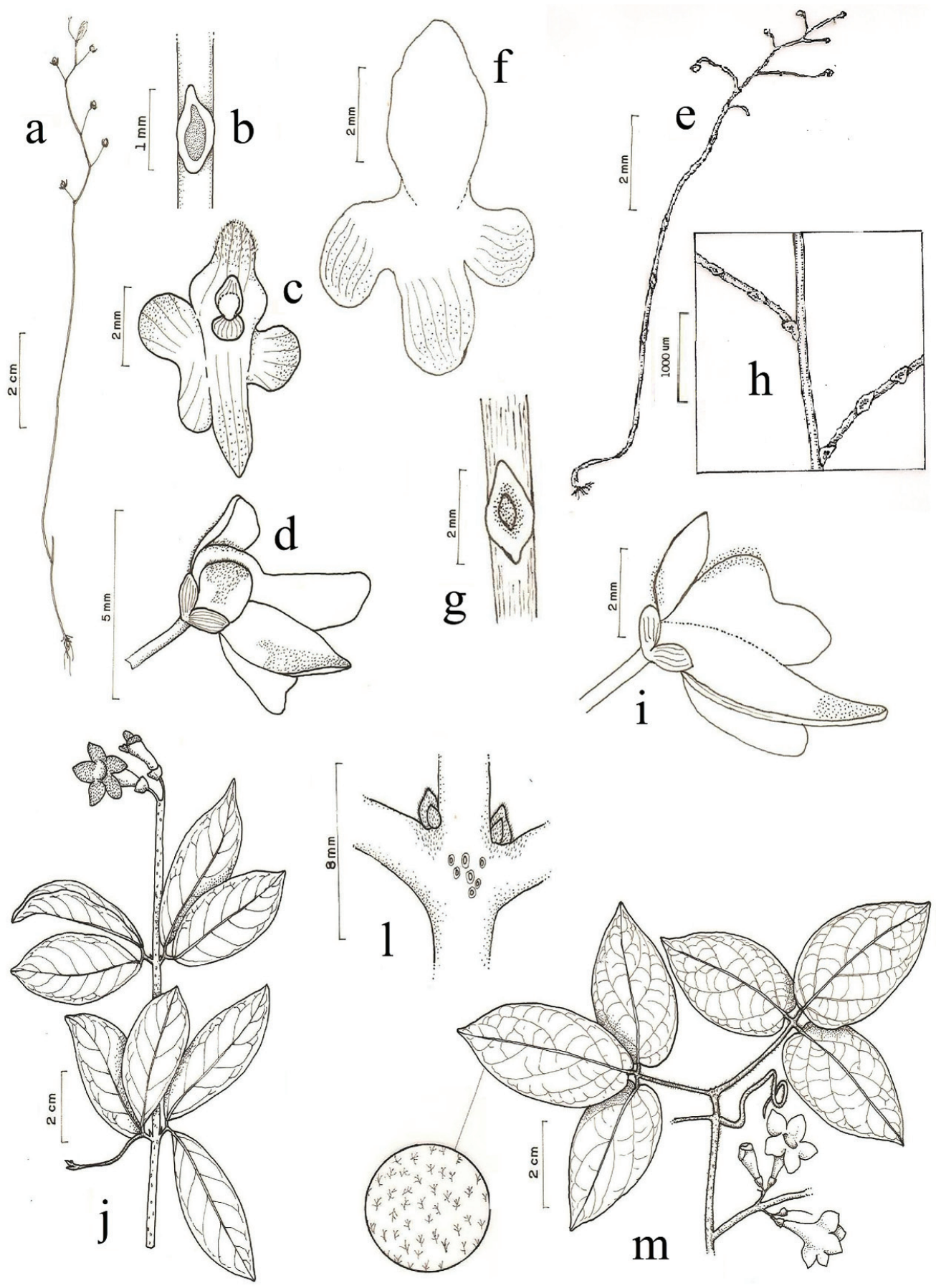

Figura 6. Espécies de Lamiales das restingas do Estado do Pará, Brasil. a-d. Utricularia subulata L. a. Racemo e escapo. b. Escama. c. Corola aberta com lábio inferior 3-lobado e lábio superior inteiro. d. Flor. (a-d: M.N.R. Furtado et al. 45). e-i. U. pusilla Vahl. e. Racemo e escapo. f. Detalhe da corola com lábio inferior 3-lobos e lábio superior inteiro. g. Escama. h. Detalhe do racemo com brácteas estéreis presentes. i. Flor. (e-i: R.M. Silva 175). j-1. Tanaecium pyramidatum (Rich.) L.G. Lohmann. j. Hábito com gavinha trífida. 1. Detalhe do ramo com estipulas e campos interpeciolares presentes. (j-1: M.N.R. Furtado et al. 39). m. Arrabidaea cinnamomea (DC.) L.G. Lohmann. m. Hábito com gavinha simples, com tricomas ramificados por toda a planta. (m: M.N.R. Furtado 38).

Figure 6. Species of Lamiales from restingas of Pará State, Brazil. a-d. Utricularia subulata L. a. Raceme and scape. b. Scale. c. Opened corolla with 3-lobed lower lip and unlobed upper lip. d. Flower. (a-d: M.N.R. Furtado et al. 45). e-i. U. pusilla Vahl. e. Raceme and scape; f. Detail of corolla with 3-lobed lower lip and unlobed upper lip. g. Scale. h. Detail of the raceme with sterile bracts. i. Flower. (e-i: R.M. Silva 175). j-1. Tanaecium pyramidatum (Rich.) L.G. Lohmann. j. Habit with trifid tendril. 1. Detail of the stem with stipules and interpetiolar glands (j-1: M.N.R. Furtado et al. 39). m. Arrabidaea cinnamomea (DC.) L.G. Lohmann. m. Habit with simple tendril and branched trichomes throughout the plant (m: M.N.R. Furtado 38). 

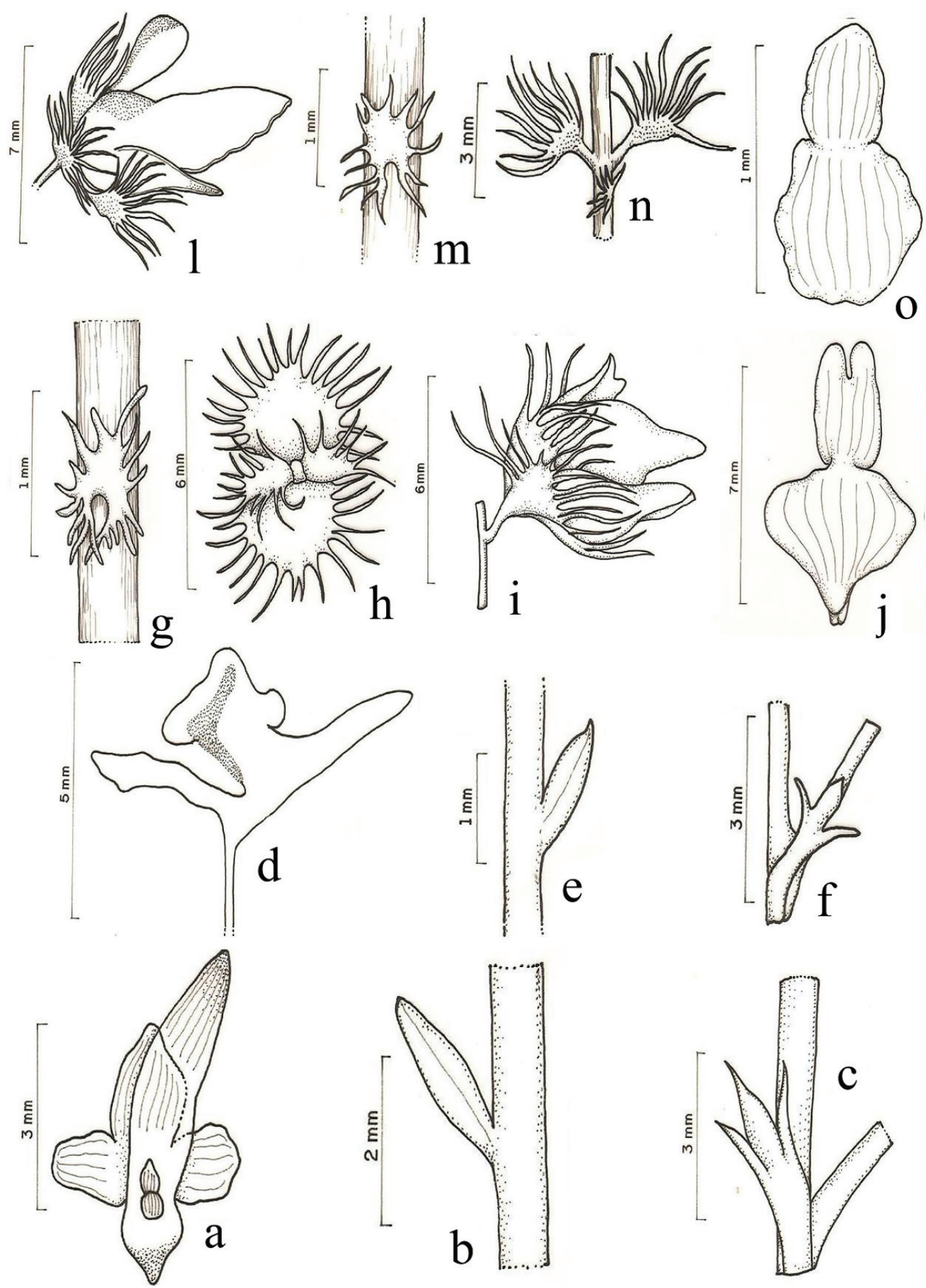

Figura 7. Espécies de Lamiales das restingas do Estado do Pará, Brasil. a-c. Utricularia amethystina Salzm. ex A.St.-Hil. \& Girard. a. Corola aberta. b. Escama. c. Bráctea (a-c: M.N.C. Bastos et al. 1651). d-f. U. tricolor A.St.-Hil. d. Corola com lábio inferior inteiro. e. Bráctea. f. Bráctea (d-f: D.T. Costa et al. 97). g-j. U. fimbriata Kunth. g. Escama. h. Cálice com bractéolas. i. Flor. j. Lábio superior 2-lobado. (g-j: M.N.C. Bastos et al. 1674). 1-o. U. simulans Pilg. 1. Corola. m. Escama. n. Bráctea e Brácteolas. o. Lábio superior e inferior da corola inteiro. (1-o: D.T. Costa et al. 99).

Figure 7. Species of Lamiales from restingas of Pará State, Brazil. a-c. Utricularia amethystina Salzm. ex A.St.-Hil. \& Girard. a. Opened corolla. b. Scale. c. Bract (a-c: M.N.C. Bastos et al. 1651). d-f. U. tricolor A.St.-Hil. d. Corolla with unlobed lower lip. e. Bract. f. Bract (d-f: D.T. Costa et al. 97). g-j. U. fimbriata Kunth. g. Scale. h. Calyx with bracteoles. i. Flower. j. 2-Lobed upper lip. (g-j: M.N.C. Bastos et al. 1674). 1-o. U. simulans Pilg. 1. Corolla. m. Scale. n. Bract and bracteoles. o. Upper and lower lips of unlobed corolla. (1-o: D.T. Costa et al. 99). 
Material examinado: BRASIL. PARÁ: Maracanã, Ilha de Algodoal/Maiandeua, campo de dunas, 23-V-2008, M.N.R. Furtado \& A.E.S Rocha 26 (MG); Maracanã, Ilha de Algodoal/Maiandeua, brejo herbáceo, 21-II-1994, M.N. Bastos et al. 1529 (MG); Maracanã, Ilha de Algodoal/Maiandeua, 9-IV-1991, M.N. Bastos et al. 775 (MG); Vizeu, Ilha de Jatium-Jabutitina, vegetação de restinga, 6-XI-1999, L.C.B. Lobato et al. 2512 (MG); Augusto Corrêa APA de Urumajó, Ilha de Porto Velho, restinga, 10-III-2001, F. Peçanha \& F. Batista 13 (MG).

Distribuição: Amazonas Ocidental, América do Sul e sudeste dos Estados Unidos (Holmgren \& Vincent 2005). Ocorre em brejo herbáceo e campo de dunas. Scoparia dulcis é uma das espécies de Scrophulariaceae mais comuns do mundo e há grande variação no formato e margem das folhas.

Alguns autores citam-na como medicinal, pois as raízes e folhas são utilizadas como diurético, em tratamentos de pedra nos rins e também em inflamações locais (Souza \& Souza 1997). Costa \& Lohmann (1999) citaram essa espécie como ornamental e medicinal, além de ser utilizada na confecção de vassouras. Floresce e frutifica entre fevereiro e novembro.

\section{VERBENACEAE}

24. Lippia alba (Mill.) N.E.Br., Bot. Porto Rico 6: 141. 1925 三 Lantana alba Mill., Gard. Dict.: 8. 1768.

Figura $4 \mathrm{~g}, \mathrm{~h}, \mathrm{i}, \mathrm{j}$

Subarbusto, ca. $27 \mathrm{~cm}$ alt., reconhecido pelas flores com corola rósea, fauce amarela, lobos irregulares, com tricomas simples, esbranquiçados, em ambas as faces, cálice 2-lobado, estigma capitado, brácteas cordadas, verdes, além do forte aroma odorífero da planta.

Material examinado: BRASIL. PARÁ: Bragança, Praia de Ajuruteua, 4-VIII-2003, R.M. Silva 81 (HCDB).

Distribuição: México, América Central, Antilhas, Colombia, Guyana, Suriname, Guiana Francesa, Peru, Brasil e Bolívia (Aymard 2005). Ocorre em dunas próximas da beira mar e manguezal. Essa espécie é um novo registro para as restingas do Estado do Pará. Floresce em agosto.

\section{Agradecimentos}

Ao CNPq, pela concessão da bolsa de Mestrado ao primeiro Autor e de produtividade ao segundo; ao
Museu Paraense Emilio Goeldi, pela infraestrutura disponibilizada para a execução desta pesquisa; ao Dr. Mário Augusto Gonçalves Jardim, pelo apoio nas excursões; ao doutorando Alessandro Rosário, pela formatação do texto; ao M.Sc. Wanderson Luís da Silva, pela formatação das figuras; e aos assessores pelas sugestões.

\section{Literatura citada}

Amaral, D.D., Prost, M.T., Bastos, M.N.C., Costa-Neto, S.V. \& Santos, J.U.M. 2008. Restingas do litoral Amazônico, Estado do Pará e Amapá, Brasil. Boletim Museu Paraense Emílio Goeldi. Ciências Naturais 3: 35-67.

Andrade, M.S., Rocha, A.E.S. \& Santos, J.U.M. 2009. A família Solanaceae. In: M.A.G. Jardim (ed.). Diversidade biológica das áreas de proteção ambiental Ilhas do Combu e Algodoal-Maiandeua, Pará, Brasil. Museu Paraense Emílio Goeldi, Belém, pp. 349-358.

Aymard C.G.A. 2005. Verbenaceae. In: J. Steyermark, P.E. Berry, K. Yatskievych, \& B.K. Holst (eds.). Flora of Venezuelan Guayana, Missouri Botanical Garden, St. Louis, v.9, pp. 407-444.

Barringer, K. \& Burger, W. 2000. Scrophulariaceae. Fieldiana, Botany 41: 1-69.

Bastos, M.N.C. 1996. Caracterização das formações vegetais da restinga da Princesa, ilha de Algodoal-PA. Tese de Doutorado, Universidade Federal do Pará, Belém.

Bastos, M.N.C., Rosário, C.S. \& Lobato, L.C.B. 1995. Caracterização fitofisionômica da restinga de Algodoal, Maracanã-PA, Brasil. Boletim Museu Paraense Emílio Goeldi, Série Botânica, 11: 173-197.

Bastos, M.N.C., Santos, J.U.M., Amaral, D.D., \& Costa-Neto, S.V. 2001. Alterações ambientais na vegetação litorânea do nordeste do Pará. In: M.T. Prost \& A.C. Mendes (eds.). Ecossistemas Costeiros: impactos e gestão ambiental. Museu Paraense Emílio Goeldi, Belém, pp. 29-38.

Corrêa, M.A. \& Mamede, M.C.H. 2002. Lentibulariaceae. In: M.G.L. Wanderley, G.J. Shepherd \& A.M. Giulietti (eds.). Flora Fanerogâmica do Estado de São Paulo, Instituto de Botânica, São Paulo, v.2, pp. 141-154.

Costa, M.A.S. \& Lohmann, L.G. 1999. Scrophulariaceae. In: J.E.L.S. Ribeiro, M.J.G. Hopkins, A. Vicentini, C.A. Sothers, M.A.S. Costa, J.M. Brito, M.A.D. Souza, L.H.P. Martins, L.G. Lohmann, P.A.C.L. Assunção, E.C. Pereira, C.F. Silva, M.R. Mesquita \& L.C. Procópio (eds.). Flora da Reserva Ducke: Guia de Identificação das plantas vasculares de uma floresta de terra-firme na Amazônia Central. Instituto Nacional de Pesquisas da Amazônia, Manaus, pp. 601. 
Costa-Neto, S.V., Bastos M.N.C. \& Lobato, C.L. 1996. Composição florística e fitofisionomia da restinga do Crispim, município de Marapanim, Pará. Boletim do Museu Paraense Emílio Goeldi, Série Botânica 12: 237-249.

Fidalgo, O. \& Bononi, V.L.R. 1984. Técnicas de coleta, preservação e herborização do material botânico. Manual, n.4. Instituto de Botânica, São Paulo.

Furtado, L.G. 1987. Curralistas e redeiros de Marudá: pescadores do litoral do Pará. Museu Paraense Emílio Goeldi, Conselho Nacional de Desenvolvimento Científico e Tecnológico, Belém.

Furtado, M.N.R., Secco, R.S. \& Rocha, A.E.S. 2009. A família Bignoniaceae. In: M.A.G. Jardim (ed.). Diversidade biológica das áreas de proteção ambiental Ilhas do Combu e Algodoal-Maiandeua, Pará, Brasil. Museu Paraense Emílio Goeldi, Belém, pp. 291-307.

Gentry, A.H. 1973. Flora of Panama. Annals of the Missouri Botanical Garden 60: 573-780.

Gentry, A.H. 1997. Bignoniaceae. In: J. Steyermark, P.E. Berry, K. Yatskievych \& B.K. Holst (eds.). Flora of Venezuelan Guayana. Missouri Botanical Garden, St. Louis, v.3, pp. 403-491.

Gibson, D.N. 1974. Lentibulariaceae. Fieldiana, Botany 24: $315-328$.

Harley, R.M. 1999. Lamiaceae. In: J. Steyermark, P.E. Berry, K. Yatskievych, \& B.K. Holst (eds.). Flora of Venezuelan Guayana. Missouri Botanical Garden, St. Louis, v.5, pp. 678-700.

Hauk, W.D. 1998. A Review of the genus Paragonia (Bignoniaceae). Annals of the Missouri Botanical Garden 85: 460-474.

Holmgren, N.H. \& Vincent, K.A. 2005. Scrophulariaceae. In: P.E. Berry, K. Yatskievych \& B.K. Holst (eds.). Flora of Venezuelan Guayana. Missouri Botanical Garden, St. Louis, v.9, pp. 46-167.

Jansen-Jacobs, M.J. \& Aymard C.G.A. 2007. Verbenaceae. In: V. Funk, T. Hollowell, P. Berry, C. Kelloff \& S.N. Alexander (eds.). Checklist of the Plants of the Guiana Shield (Venezuela: Amazonas, Bolivar, Delta Amacuro; Guyana, Surinam, French Guiana). Contribution from the United States National Herbarium 55: 1-584.

Lohmann, L.G. \& Hopkins, M.J.G. 1999. Bignoniaceae. In: J.E.L.S. Ribeiro, M.J.G. Hopkins, A. Vicentini, C.A. Sothers, M.A.S. Costa, J.M. Brito, M.A.D. Souza, L.H.P. Martins, L.G. Lohmann, P.A.C.L. Assunção, E.C. Pereira, C.F. Silva, M.R. Mesquita \& L.C. Procópio (eds.). Guia de identificação das plantas vasculares de uma floresta de Terra Firme na Amazônia Central. Flora da Reserva Ducke. INPA Instituto Nacional de Pesquisas da Amazônia, Manaus, pp. 608-623.
Lohmann, L.G. 2012. Bignoniaceae. In: R.C. Forzza, A. Costa, B.M.T. Walter, J.R. Pirani, M.P. Morim, L.P. Queiroz, G. Martinelli, A.L. Peixoto, M.A.N. Coelho, J.F.A. Baumgratz, J.R. Stehmann, L.G. Lohmann \& M. Hopkins (eds.). Lista de Espécies da Flora do Brasil. Jardim Botânico do Rio de Janeiro. http://floradobrasil. jbrj.gov.br/2012/FB025964 (acesso em 19.09.2012).

Lopes, N.S., Rocha, A.E.S. \& Bastos, M.N.C. 2009. A família Ochnaceae. In: M.A.G. Jardim (ed.). Diversidade biológica das áreas de proteção ambiental Ilhas do Combu e Algodoal-Maiandeua, Pará, Brasil. Museu Paraense Emílio Goeldi, Belém, pp. 321-332.

Margalho, L.F., Rocha, A.E.S \& Secco, R.S. 2009. Rubiaceae Juss. da restinga da APA de Algodoal/ Maiandeua, Pará, Brasil. Boletim do Museu Paraense Emilio Goeldi, Ciências Naturais 4: 303-339.

Martins, F.S., Bastos, M.N.C. \& Rocha, A.E.S. 2009. A família Chrysobalanaceae. In: M.A.G. Jardim (ed.). Diversidade biológica das áreas de proteção ambiental Ilhas do Combu e Algodoal-Maiandeua, Pará, Brasil. Museu Paraense Emílio Goeldi, Belém, pp. 309-319.

Martorano, L.G., Pereira, L.C., César, E.G.M., Pereira, I.C.B., Santos, E.C.R., Santos, F.A.C., Moraes, W.F.M., Nery, F.A.S., Rodrigues, T.E. \& Rolim, P.A.M. 1993. Estudos climáticos do Estado do Pará, classificação climática (Köppen) e deficiência hídrica (Thornthwhite, Mather). Superintendência de Desenvolvimento da Amazônia, Empresa Brasileira de Pesquisas Agropecuárias, Serviço Nacional de Levantamento e Conservação de Solos, Belém.

Mesquita, A.S., Rocha, A.E.S. \& Santos, J.U.M. 2009. A família Polygalaceae. In: M.A.G. Jardim (ed.). Diversidade biológica das áreas de proteção ambiental Ilhas do Combu e Algodoal-Maiandeua, Pará, Brasil. Museu Paraense Emílio Goeldi, Belém, pp. 333-347.

Mittelstaedt, C.A. 2008. Filogenia do gênero Utricularia L. (Lentibulariaceae) utilizando caracteres morfológicos e moleculares pelo método de otimização direta. Dissertação de Mestrado, Universidade de Mogi das Cruzes, Mogi das Cruzes.

Moldenke, H.N. 1973. Avicenniaceae. Annals of the Missouri Botanical Garden 60: 149-154.

Nowicke, J.W. \& Epling, C.C. 1969. Family 169. Labiatae. Annals of the Missouri Botanical Garden, St. Louis, pp. 71-111.

Oliveira, J.A., Rocha, A.E.S \& Bastos, M.N.C. 2009. A família Arecaceae. In: M.A.G. Jardim (ed.). Diversidade biológica das áreas de proteção ambiental Ilhas do Combu e Algodoal-Maiandeua, Pará, Brasil. Museu Paraense Emílio Goeldi, Belém, pp. 245-267.

Olvera G.M. 1996. El género Utricularia (Lentibulariaceae) en México. Anales del Instituto de Biologia, Universidad Nacional Autónoma de México, Serie Botánica 67: 347-384. 
Pires, J.M. 1973. Tipos de vegetação da Amazônia. O Museu Goeldi no ano do Sesquicentenário. Publicação Avulsa do Museu Paraense Emílio Goeldi 20: 179-202.

Pool, A. 2009. A review of the genus Distictella (Bignoniaceae). Annals of Missouri Botanical Garden 96: 286-323.

Pott, V.J. \& Pott, A. 2000. Lentibulariaceae. In: V.J. Pott \& A. Pott (eds.). Plantas Aquáticas do Pantanal. Empresa Brasileira de Pesquisas Agropecuárias, Brasília, pp. 180-188.

Rocha, A.E.S. \& Bastos, M.N.C. 2004. Flora fanerogâmica das restingas do Estado do Pará. APA de Algodoal/ Maiandeua. II - Eriocaulaceae P. Beauv. ex Desv. Hoehnea 31: 103-111.

Rocha, A.E.S. 2000. Poaceae na restinga da praia da Princesa, APA de Algodoal/Maiandeua, Maracanã-PA. Dissertação de Mestrado, Universidade Federal Rural da Amazônia, Belém.

Rosário, A.S., Secco, R.S., Amaral, D.D., Santos, J.U. \& Bastos, M.N.C. 2005. Flórula Fanerogâmica das Restingas do Estado do Pará. Ilhas de Algodoal e Maiandeua. III - Myrtaceae R. Br. Boletim do Museu Paraense Emílio Goeldi, Série Botânica 1: 31-48.

Sandwith, N.Y. \& Hunt, D.R. 1974. Bignoniáceas. In: R. Reitz (ed.). Flora Ilustrada Catarinense. Herbário Barbosa Rodrigues, Itajaí.

Santos, J.U.M. \& Rosário, C.S. 1988. Levantamento da vegetação fixadora das dunas de Algodoal - PA. Boletim do Museu Paraense Emílio Goeldi, Série Botânica 4: 133-151.

Souza Filho, P.W.M., Cunha, E.R.S.P., Sales, M.E.C., Souza, L.F.M.O. \& Costa, F.R. 2005. Bibliografia da zona costeira amazônica. Museu Paraense Emilio Goeldi, Universidade Federal do Pará, Petrobrás, Belém.

Souza, V.C. \& Giulietti, A.M. 2003. Flora da Serra do Cipó, Minas Gerais: Scrophulariaceae. Boletim de Botânica da Universidade de São Paulo 21: 283-297.

Souza, V.C. \& Giulietti, A.M. 2009. Levantamento das espécies de Scrophulariaceae sensu lato nativas do Brasil. Pesquisa Botânica 60: 7-288.
Souza, V.C. \& Souza, J.P. 1997. Scrophulariaceae. In: J.A. Rizzo (ed.). Flora dos Estados de Goiás e Tocantins. Universidade Federal de Goiás, Goiânia, v.22, pp. 7- 83.

Souza, V.C. 2012. Plantaginaceae. In: R.C. Forzza, A. Costa, B.M.T. Walter, J.R. Pirani, M.P. Morim, L.P. Queiroz, G. Martinelli, A.L. Peixoto, M.A.N. Coelho, J.F.A. Baumgratz, J.R. Stehmann, L.G. Lohmann \& M. Hopkins (eds.). Lista de Espécies da Flora do Brasil. Jardim Botânico do Rio de Janeiro. http://floradobrasil. jbrj.gov.br/2012/FB025964 (acesso em 19.09.2012).

Sudam/PHCA. 1984. Atlas Climatológico da Amazônia Brasileira. Superitendência de Desenvolvimento da Amazônia, Belém.

Taylor, P. 1964. The genus Utricularia L.(Lentibulariaceae) in Africa (south of the Sahara) and Madagascar. Kew Bulletin 18: 1-245.

Taylor, P. 1976. Lentibulariaceae. In: R.E. Woodson, \& R.W. Schery (eds.). Flora of Panamá. Part IX. Annals of the Missouri Botanical Garden 63: 565-580.

Taylor, P. 1989. The genus Utricularia - a taxonomic monograph. Kew Bulletin, Additional Series XIV. 2 ed. Royal Botanic Gardens, Kew.

Taylor, P. 1999. Lentibulariaceae. In: J. Steyermark, P.E. Berry, K. Yatskievych \& B.K. Holst (eds.). Flora of Venezuelan Guayana. Missouri Botanical Garden, St. Louis, v.5, pp. 782-803.

The Angiosperm Phylogeny Group (APG III). 2009. An update of the Angiosperm Phylogeny Group classification for the orders and families of flowering plants: APG III. Botanical Journal of the Linnean Society 161: 105-121.

Vicente, A.C.A., Macedo, E.G., Santos, J.U.M., Potiguara, R.V. \& Bastos, M.N.C. 1999. Flora Fanerogâmica das Restingas do Estado do Pará. Ilhas de Algodoal 1 - Família Turneraceae A.P. de Candolle. Boletim do Museu Paraense Emílio Goeldi, Série Botânica 15: 173-198.

Wasshausen, D.C. 1995. Acanthaceae In: J. Steyermark, P.E. Berry, K. Yatskievych \& B.K. Holst (eds.). Flora of Venezuelan Guayana. Missouri Botanical Garden, St. Louis, v.2, pp. 335-373.

Wessel, P. \& Smith, W.H.F. 1996. A global self-consistent, hierarchical, high-resolution shoreline database. Journal of Geophysical Research 101: 8741-8743. 
